\title{
Emergence of HIV types and risk factors in pregnant women in burkina faso from 2006 to 2014
}

\begin{abstract}
Introduction: The co-circulation of the two types of HIV leads to dual infections (HIV-1 +2 ). Their detection therefore seems essential to a better allocation of resources within the infected population. The goal of the study was to determine the prevalence of HIV types over the years and identify factors associated with co-circulation of HIV-1, HIV-2 and HIV $1+2$ in Burkina Faso.
\end{abstract}

Material and methods: A total of 66597pregnant women from 13 health regions in Burkina Faso participated in the study from 2006 to 2014. Their blood samples were analyzed for the detection of HIV antibodies according to Strategy II WHO / UNAIDS, using the mixed test Vironostika HIV Uniform II Plus O (Bio-Merieux) and the discriminant test ImmunoCombII HIV-1 \& 2 BiSpot (Orgenics). The samples that gave discordant results between the two tests, and those who were positive for HIV-2 or HIV $1+2$ were subjected to confirmatory testing HIV BLOT 2.2 (MP Diagnostics). Socio-demographic data among the participants were correlated with their HIV status to identify risk factors.

Results: The HIV rates were respectively $(97.9 \%-90.0 \%)$ for HIV-1 $(5.55 \%-2.1 \%)$ for HIV-2 and $(4.44 \%-0 \%)$ for HIV-1+2. HIV-1 levels were significantly higher $(40.2 \%)$ $(\mathrm{p}=0.001)$ in Ouagadougou in urban areas. The peaks were $83.3 \%$ in Kaya and $37.5 \%$ in Ziniare respectively for HIV-2 and HIV-1+2. Risk factors associated with the type of HIV were being married with $\left(\mathrm{OR}\right.$, odds ratio $=65.4^{54.8}$ to 78.0 for HIV-1 against $47.7^{22.4}$ to 101.7 for HIV-2; having one or more parity (OR=12.6 ${ }^{10.7}$ to 14.7 for HIV-1 versus $2.2^{1.02}$ to 5.07 for HIV2). All other types of occupation met in relation to pupils and students $1.8^{1.2-2.6} ; p=0.001$ ) for HIV-1 and occupation did not constitute a risk to the HIV-2 (OR=1.1 $\left.1^{0.2 \text { to } 4.7}, \mathrm{p}=0.85\right)$; be illiterate HIV-D $\left(\mathrm{OR}=137.5^{17.5 \text { to } 1074.7} ; \mathrm{p}=0.000\right)$ and enrollment was not a risk for HIV-1 $\left(\mathrm{OR}=1^{0,7-1,3}, \mathrm{p}=0.9\right)$ and HIV-2 (OR=3.2 $\left.{ }^{0.4 \text { to } 23.3} ; \mathrm{p}=0.2\right)$; be aged 20-49 for HIV-1 (OR=72.9 56.4 to 94.3$)$ and HIV-2 (OR=2.7 ${ }^{1.002}$ to 7.6$)$ and finally residence time of one year or more in the health community for HIV-1 $\left(\mathrm{OR}=4.3^{3.7 \text { to } 5.1} ; \mathrm{p}=0.000\right)$ compared to less than one year and was no risk for HIV-2 (OR 1.0 $\left.{ }^{0.4-2.5} ; \mathrm{p}=0.8\right)$ and HIV-D $\left(\mathrm{OR}=1.0^{0.2 \text { to } 4.4} ; \mathrm{p}=0.9\right)$.

Conclusion: HIV-1 was still predominant in Burkina Faso and had a higher risk compared to HIV-2. The rates of different types of HIV were significantly variable depending on the socio-demographics characteristics of women. Taking account of these differences raised in the distribution of resources greatly improves the care of people living with HIV in Burkina Faso.

Keywords: HIV1, HIV2, VIHD, pregnant women, burkina faso risk factors
Volume 5 Issue 2 - 2017

Konate D, ${ }^{1,2}$ Dahourou $\mathrm{H},{ }^{3}$ Ouedraogo $\mathrm{C}$,' Bambara Kankouan A,' Somda A, ${ }^{4}$ Guired A, ${ }^{4}$ Sanou MJ, ${ }^{4}$ Barro N, ${ }^{2}$ Traore AS, ${ }^{2}$ Sangare L ${ }^{1,5}$ 'Department of Bacteriology-Virology, University Hospital Yalgado Ouedraogo, Burkina Faso

${ }^{2}$ Faculty of Life Sciences and Earth, University of Ouagadougou, Burkina Faso

${ }^{3}$ National Blood Transfusion Center, Burkina Faso

${ }^{4}$ Health Sector Program for the Fight against AIDS and Sexually Transmitted Infections (STI-PSSLS), Burkina Faso

${ }^{5}$ Faculty of Health Sciences, University of Ouagadougou, Burkina Faso

Correspondence: Konate Djelika, Department of Bacteriology-Virology, University Hospital Yalgado Ouedraogo, CHU-YO, 03 BP, 03 BP 7022, Ouagadougou 03, Burkina Faso, Email djelika7@yahoo.fr

Received: June 04, 2017 | Published: June 26, 2017

\section{Introduction}

HIV-1 first to be discovered , ${ }^{1,2}$ is more prevalent than HIV-2.3.5 This explains the direction of research into HIV-1 since 1984 for its diagnosis and in particular by ELISA(Enzyme-Linked Immunosorbent Assay) and Western Blot for the detection of antibodies, antigenemia $\mathrm{P} 24, \mathrm{PCR}^{6}$ or the cell culture ${ }^{7}$ to treatment including molecular research by deciphering of its genome, viral load and resistance to antiretroviral. ${ }^{8-11}$ This is followed by determining its impact techniques $^{8,11}$ from the 2000s to the present. The consequence of all these efforts is a reduction of is the reduction of HIV-1 prevalence ${ }^{12,13}$ over the years. However, HIV-2 discovered a few years later raged mainly in West Africa ${ }^{14,15}$ and recorded a low prevalence. ${ }^{16,17}$ Burkina Faso is among the countries where HIV prevalence is moderate. The average national HIV prevalence in Burkina Faso obtained through the monitoring of sentinel sites was falling since 2009. Knowledge of the facets of the epidemic can develop specific strategies to refine the management and monitoring of people living with HIV. The therapeutic management of people living with HIV necessarily involves identifying the types of HIV (HIV-1, HIV-2 or HIV-1+2). Tests have been developed for this purpose, however, it remains false positive or negative results or indeterminate, ${ }^{18,19}$ due to the co- circulation of both virus types one hand and the specific kits for the HIV-1 second. ${ }^{20-22}$ Thus, appropriate tests may reveal the presence of a double HIV-1 +2 infections. The molecular differences (50 to $60 \%$ ) between HIV-1 and HIV-2 ${ }^{14}$ can be use to counter act the outbreak of the infection (for example HIV-2 infection can protect against HIV-1 infection), their pathogenicity 1 to 23 and their replication properties determine the choice of antiretroviral drugs. ${ }^{23-26}$ The co-circulation of these HIV-1 and HIV-2 variants differing leads to dual infections (HIV-D). Their detection thus appears essential. The goal of the study was to determine the prevalence of HIV types over the years and identify factors associated with co-circulation of HIV-1, HIV-2 and HIV $1+2$ in Burkina Faso.

\section{Materials and methods}

\section{Study sites}

The study was conducted in thirteen (13) health regions of Burkina Faso (Figure 1): the Mouhoun, Cascades, Central, East Central, North Central, Central West, the Centre- South East, the Hauts Bassins, North, Central Plateau, the Sahel and the Southwest. Serological analyzes were performed at the National Reference Laboratory for HIV/AIDS and sexually transmitted infections (NRL-HIV / AIDS- 
STI) in the Bacteriology-Virology Department of the University Hospital Yalgado Ouedraogo (CHU-YO).

\section{Localisation des sites de prélèvements}

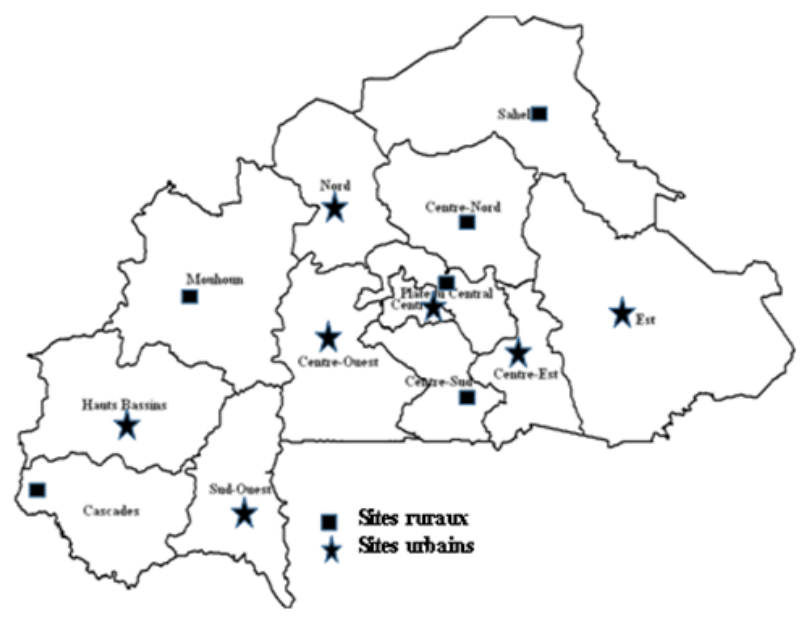

Figure I Location of sampling sites.

\section{Type and duration of the study}

The study was retrospective analytical referred. It covered a period of nine years from 2006 to 2014.

\section{Populations and sampling}

The population represented the pregnant women aged 15 to 49 years who were enrolled consecutively until the size of the recommended sample, including 800 in Ouagadougou in the DRS Center and BoboDioulasso, respectively, and 400 each of the other sites.

\section{Data gathering}

Ten milliliters of whole blood taken in sterile dry tube from each pregnant woman was centrifuged to collect serum was aliquoted into a sterile cryovial and stored at $-20^{\circ} \mathrm{C}$ prior to transfer to the NRL-HIV/ AIDS-STI. A questionnaire was administered to all consenting women to collect sociodemographic data. These documents accompanied the samples to the NRL-HIV/AIDS-STI for serological and statistical analysis.

\section{Serological}

Sera were analyzed according to strategy II detecting HIV WHO / UNAID illustrated in Figure 1. ${ }^{27}$ Briefly, each serum was analyzed by a very sensitive mixed first test (T1), the Vironostika HIV Uniform II Plus O (Bio-Merieux, France); Any sample found negative in this test was rated "negative". Those found positive were analyzed by the discriminating test (T2) ImmunoCombII HIV1 \& 2 BiSpot (Orgenics) to determine the type (s) of HIV (HIV-1, HIV-2 and HIV-D: HIV-1 +2 ). All discordant results between the two tests were classified as "undetermined" temporarily. These sera, those of HIV-D and HIV-2 positive were subjected to confirmatory testing HIV BLOT 2.2 (MP Diagnostics) the results obtained by Western blotting were performed according to the WHO criteria ${ }^{27}$ and made positive (HIV-1, HIV-2 or HIV-D), negative or indeterminate.

\section{Ethical considerations}

All women enrolled were informed verbally of the object of the study. The study used the unlinked anonymous testing of the WHO. ${ }^{28,29}$ Their participation was voluntary and no information on their identity was not mentioned on the samples. The anonymous unique numbering of each sample was correlated with sociodemographic questionnaire for each participant.

\section{Statistical analysis of data}

The data obtained from the study were analyzed using the software Epi Info version 3.5.2, version 7 and the XLSTAT software for multiple comparison tests. The statistical significance was considered at $\mathrm{p}=0.05$ with the $\mathrm{X} 2$ Friedman.

\section{Results}

\section{Demographic characteristics of the study population}

A total of 66,597 pregnant women attended the sero-surveillance in the study period, with an average of 7399.66. For the average values $60,737 / 66,560$ married women $(91.2 \%)$ were the most represented unlike other statutes including 5,730/66,560 single (8.6\%), the widows $28 / 66,560(0.04 \%)$ and the divorced $12 / 66,560(0.01 \%)$. The majority of women were respectively $0(27.1 \%), 1(23.3 \%)$ and 2 children $(18.8 \%)$. The median parity was 2 children with extremes ranging from 2 to 14 children. Average rates were among $57,397 / 66,572$ housewives $(86.2 \%)$ followed by pupils and students $3,276 / 66,572(4.9 \%)$, shopping $2,558 / 66,572(3.8 \%)$, civil servants and employees 1,203 / 66,572(1.8\%) and 651/66,572 artisans (0.9\%).

The average rates of education were $14.87 \%$, respectively $(9,850 / 66,225$ for 9 years combined) for primary, $13.72 \%$ $(9,090 / 66,225)$ secondary, $1.25 \%(830 / 66,225)$ greater than $6539 \%$ $(43,306 / 66,225)$ non-literate and $4.75 \%(3,149 / 66,225)$ literate during the nine years of collecting. Women with a residence time of a year or more in their health region were on average $88.4 \%(58,804 / 66,467)$ of the study population.

The median age was 24 years for the nine years of serosurveillance of HIV, with a range from 15 to 49 years. An average $55.8 \%$ $(37,151 / 66,568)$ of the women surveyed were from the age group of 20-29 years, while $17.8 \%(11,892 / 66,568)$ were aged $15-19$ years.

\section{Rate of HIV-I, HIV-2 and HIV-I + 2 (HIV-D) by year}

HIV rates ranged from $97.9 \%$ to $90.0 \%$ for HIV-1, $5.55 \%$ to $2.1 \%$ (HIV-2) and $4.44 \%$ to $0 \%$ (HIV-D). The difference was statistically significant $(\mathrm{p}=0.000)$ (Table 1$)$.

\section{Change in HIV-I levels, HIV-2 and HIV-D according demographics}

There were significant differences in demographic characteristics among women with HIV-1, HIV-2 and HIV-D during the study period (Table 2).

HIV-1 levels were significantly higher $(40.2 \%)$ in the capital of Burkina Faso (Ouagadougou) versus that of HIV-2 which had its maximum $(22.7 \%)$ in Ouahigouya $(\mathrm{p}=0.001)$ (Table 3). In rural areas, the maximum rate of HIV-1 (23.7\%) was observed in Sindou against the HIV2 (83.3\%) to Kaya and HIV-D (37.5\%) in Ziniaré. The difference was statistically significant $(\mathrm{p}=0.007)$ (Table 4).

The majority of women infected with HIV-1 (386 [36.4\%] of 1,059), HIV-2 (13 [23.6\%] of 55) and HIV-D (7 [43.7\%] 16), were aged 25-29 years against the lowest proportion $1.8 \%$ (HIV-2), $0.1 \%$ (HIV-1) and 0\% (HIV-D) observed among 45-49. HIV1 rate increased with age up to 29 years and decreases with age after 29 years. He HIV2 was stable at $23.6 \%$ between $25-34$ years $(\mathrm{p}=0.001)($ Table 5$)$.

The rates were significantly higher for HIV-1 (261 [25\%] of 1043), HIV-D (4 [25\%] of 16) and HIV-2 (12 [23.5\%] of 51) in women had 1 child. HIV-1 rate conversely decreases with parity from 1 child $(\mathrm{p}=$ 
0.001) (Table 6). Household recorded significantly high rates of each of HIV infections $82.2 \%$, respectively (HIV-1), 66.6\% (HIV-2) and $38.4 \%$ (HIV-D) ( $\mathrm{p}=0.002$ ) against the low levels of HIV-1 within the window display $(0.1 \%)$ of HIV-2 (0\%) among artisans and HIV-D $(0 \%)$ (artisans, shopping and pupils / students) (Table 7).

HIV-D rate was $100 \%$ among married women against $86.2 \%$ for HIV-1 and $84.0 \%$ (HIV-2). The difference was statistically significant between HIV-1, HIV-2 and HIV-D ( $p=0.0004)$.

The rate was significantly higher among illiterate women $55.2 \%$ respectively (HIV-1), 71.1\% (HIV-2) and 71.4\% (HIV-D) against literate and among those with the primary level $21.2 \%$ (HIV-1), $13.4 \%$ (HIV-2) and $14.2 \%$ (HIV-D) against the superior level ( $\mathrm{p}=$ 0.008 ) (Table 8).
Pregnant women had respectively 65.4 times the risk of infection by HIV-1 and 47.7 by HIV-2 compared to unmarried women. Women with parity 1 or more had 12.6 times the risk of infection by HIV-1 and 2.2 times by HIV-2 compared to women who had parity 0 . Other types of occupations had 1.8 times the risk of infection by HIV-1 compared to pupils and students and occupation was not a risk to HIV-2. The illiterate women were 137.5 times the risk of HIV infection compared to literate women and schooling was not a risk for HIV-1 and HIV-2. Women aged 20-49 had 72.9 times the risk of infection by HIV-1 and 2.7 times for HIV-2 compared to those aged 15-19. Women who have a residence time of a year or more in their health locality had 4.3 times the risk of infection by HIV-1 compared to those who have less than a year. The length of stay was not a risk to HIV-2 and HIV-D infection (Table 9).

Table I Result of screening according to the type of HIV obtained

\begin{tabular}{|c|c|c|c|c|c|c|c|}
\hline Year & $\begin{array}{l}\text { Number } \\
\text { Positive }\end{array}$ & $\begin{array}{l}\text { HIV-I } \\
\text { Number }\end{array}$ & (\%) & $\begin{array}{l}\text { HIV-2 } \\
\text { Number }\end{array}$ & $\%$ & $\begin{array}{l}\text { HIV-D } \\
\text { Number }\end{array}$ & $\%$ \\
\hline 2006 & 200 & 186 & -93 & 10 & -5 & 4 & -2 \\
\hline 2007 & 167 & 160 & -95.8 & 7 & -4.19 & 0 & 0 \\
\hline 2008 & 161 & 152 & -94.4 & 7 & -4.34 & 2 & -1.24 \\
\hline 2009 & 160 & 146 & -91.25 & 8 & -5 & 6 & -3.75 \\
\hline 2010 & 130 & 124 & -95.38 & 6 & $-4.6 I$ & 0 & 0 \\
\hline 2011 & 130 & 124 & -95.38 & 6 & -4.61 & 0 & 0 \\
\hline 2012 & 122 & 116 & -95.08 & 4 & -3.27 & 0 & 0 \\
\hline 2013 & 90 & 81 & -90 & 5 & -5.55 & 4 & -4.44 \\
\hline 2014 & 95 & 93 & -97.89 & 2 & -2.1 & 0 & 0 \\
\hline Total & 1255 & 1182 & -94.18 & 55 & $(4,3)$ & 16 & -1.27 \\
\hline
\end{tabular}

$p=0.000 ;$ Chi $2=18$.

Table 2 The HIV-I infection, HIV-2 and HIV-D according to urban areas

\begin{tabular}{|c|c|c|c|c|c|}
\hline Urban Areas & Positive HIVI (N = 979) & Positive HIV2 (N = 44) & HIVI + 2 Positive $(\mathbf{N}=8)$ & $\mathbf{P}$ & Chi2 \\
\hline High Basins (Bobo dioulasso) & $193(19.7)$ & $6(13.6)$ & I (12.5) & 0,001 & 0 \\
\hline South West (Gaoua) & $85(8.6)$ & $6(13.6)$ & 0 & & \\
\hline Center (Ouagadougou) & $394(40.2)$ & $8(18.18)$ & $2(25.0)$ & & \\
\hline North (Ouahigouya) & $89(9.09)$ & $10(22.7)$ & 0 & & \\
\hline East Central (Tenkodogo) & $47(4.8)$ & $5(\mid \mathrm{I} .3)$ & I (12.5) & & \\
\hline
\end{tabular}

Table 3 the HIV-I infection, HIV-2 and HIV-D according rural

\begin{tabular}{|c|c|c|c|c|c|}
\hline Rural & HIV - I-P & HIV -2 Positive $(\mathrm{N}=6)$ & Vihd Positive $(\mathbf{N}=\mathbf{8})$ & $\mathbf{P}$ & Chi2 \\
\hline Mouhoun (Dédougou) & $30(16.2)$ & I (I6.66) & I (I2.5) & 0,007 & 9.8 \\
\hline Sahel (Dori) & $10(5.4)$ & 0 & I (12.5) & & \\
\hline North Central (Kaya) & $36(19.45)$ & $5(83.33)$ & I (12.5) & & \\
\hline South Center (Manga) & $26(14.05)$ & $2(33.33)$ & $2(25.0)$ & & \\
\hline Cascades (Sindou) & $44(23.7)$ & I (I6.66) & 0 & & \\
\hline Central Plateau (Źiniaré) & $39(21.08)$ & $2(33.33)$ & $3(37.5)$ & & \\
\hline
\end{tabular}

Table 4 Infections in HIV-I, HIV-2 and HIV-D according to the age groups of pregnant women in Burkina Faso

\begin{tabular}{|c|c|c|c|c|c|}
\hline Age Group (Year) & HIV-I Positive (N = I,059) & HIV-2 Positive $(\mathbf{N}=55)$ & VIHD Positive (N = I6) & $\mathbf{P}$ & Chi2 \\
\hline $15-19$ & $62(5.8)$ & $4(7.2)$ & $x_{1}$ & 0,001 & 14 \\
\hline $20-24$ & $147(13.7)$ & $10(18.1)$ & $2(12.5)$ & & \\
\hline $25-29$ & $386(36.4)$ & $13(23.6)$ & $7(43.7)$ & & \\
\hline $30-34$ & $299(28.2)$ & $13(23.6)$ & $2(12.5)$ & & \\
\hline $35-39$ & $145(13.6)$ & $10(18.1)$ & $3(18.7)$ & & \\
\hline $40-44$ & $18(0.9)$ & $4(7.2)$ & $2(12.5)$ & & \\
\hline $45-49$ & $2(0.1)$ & $\mathrm{I}(\mathrm{I} .8)$ & 0 & & \\
\hline
\end{tabular}

Table 5 Infections in HIV-I, HIV-2 and HIV-D by parity among pregnant women in Burkina Faso

\begin{tabular}{|c|c|c|c|c|c|}
\hline Parity & HIV-I Positive ( $N=$ I 043) & HIV-2 Positive $(\mathbf{N}=5 \mathrm{I})$ & HIV I + 2 Positive $(N=16)$ & $\mathbf{P}$ & Chi2 \\
\hline 0 & $194(18.6 \%)$ & $7(13.7)$ & 0 & 0,001 & 14 \\
\hline I & $26 \mathrm{I}(25.0)$ & $12(23.5)$ & $4(25.0)$ & & \\
\hline 2 & $232(22.2)$ & $6(11.7)$ & $3(18.7)$ & & \\
\hline 3 & $153(14.6)$ & $4(7,8)$ & $3(18.7)$ & & \\
\hline 4 & $97(9.3)$ & $8(15.6)$ & $2(12.5)$ & & \\
\hline 5 & $63(6.0)$ & $4(7,8)$ & I (6.25) & & \\
\hline 6 or more & $43(4.1)$ & $10(19.6)$ & $3(18.7)$ & & \\
\hline
\end{tabular}


Table 6 Infections in HIV-I, HIV-2 and HIV-D according to the marital status of women in Burkina Faso

\begin{tabular}{|c|c|c|c|c|c|}
\hline Marital Status & HIV-I Positive $(\mathrm{N}=$ I 066) & HIV-2 Positive $(\mathbf{N}=50)$ & Positive HIV-D $(\mathbf{N}=16)$ & $\mathbf{P}$ & Chi2 \\
\hline Married & $919(86.2)$ & $42(84.0)$ & $16(100.0)$ & 0.0004 & 24.6 \\
\hline Single & $143(13.4)$ & $7(\mid 4.0)$ & 0 & & \\
\hline Widow & 0 & I (2.0) & 0 & & \\
\hline Divorced & 0 & 0 & 0 & & \\
\hline concubinage & $4(0.3)$ & 0 & 0 & & \\
\hline
\end{tabular}

Table 7 Infection by HIV-I, HIV-2 and HIV-D according to the employment of women

\begin{tabular}{|c|c|c|c|c|c|}
\hline Occupations & HIV - I Positive $(\mathrm{N}=\mathrm{I}, 060)$ & HIV -2 Positive $(\mathrm{N}=45)$ & HIV -D Positive $(\mathrm{N}=$ I3) & $\mathbf{P}$ & Chi2 \\
\hline Crafts Woman & $21(1.9)$ & 0 & 0 & 0,002 & 12 \\
\hline Shopping & $65(6.1)$ & $4(8.8)$ & 0 & & \\
\hline Pupil / Student & $29(2.7)$ & $2(4.4)$ & 0 & & \\
\hline Etalagiste & $2(0.1)$ & I (2.2) & I (7.6) & & \\
\hline Official & $31(2.9)$ & $8(17.7)$ & $5(38.4)$ & & \\
\hline Household & $872(82.2)$ & $30(66.6)$ & $5(38.4)$ & & \\
\hline Other & $40(3.7)$ & 0 & $2(15.3)$ & & \\
\hline
\end{tabular}

Table 8 Infection with HIV-I, HIV-2 and HIV-D by education women

\begin{tabular}{|c|c|c|c|c|}
\hline Schooling & HIV-I Positive $(\mathbf{N}=1,066)$ & HIV-2 Positive ( $\mathbf{N}=52$ ) & Positive HIV-D (N = I4) P & Chi2 \\
\hline Literate & $42(3.9)$ & I (I.9) & I (7.I) & 9.5 \\
\hline No Literate & $589(55.2)$ & 37 (7I.I) & $10(71.4)$ & \\
\hline Primary & $227(2 \mid .2)$ & $7(13.4)$ & $2(14.2)$ & \\
\hline Secondary & $197(18.4)$ & $5(9.6)$ & I (7.I) & \\
\hline Superior & II (I.0) & $2(3.8)$ & 0 & \\
\hline
\end{tabular}

Table 9 Odds Ratio=OR

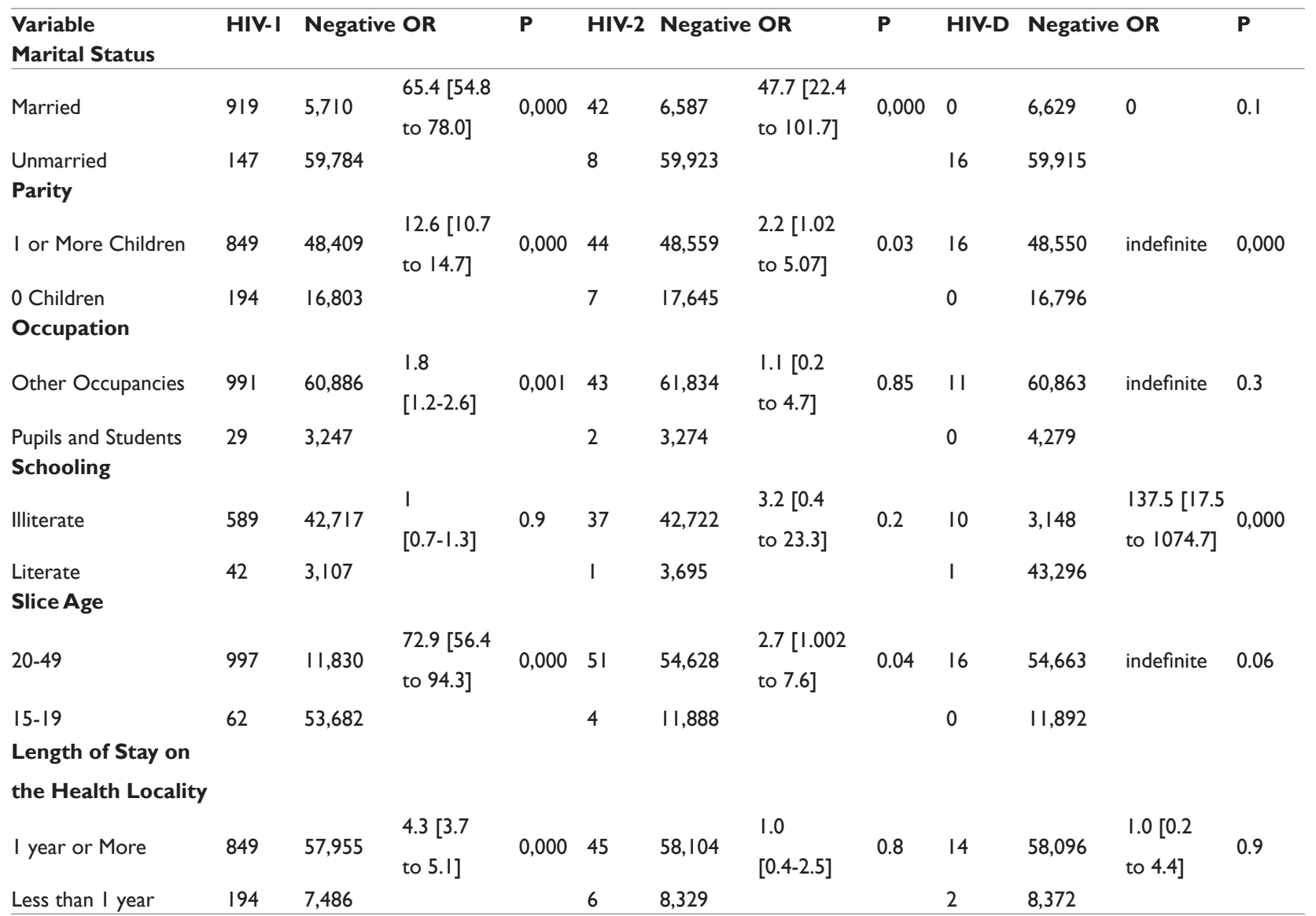

\section{Discussion}

\section{Demographics women}

Rates are calculated according to the results of socio-demographic characteristics available. Some of these features have not been informed about the survey sheets at the time of sample collection, the frequencies of HIV-1, HIV-2 and HIV-D will vary depending on the available parameters. 


\section{Rate of HIV-I, HIV-2 and HIV-D}

Burkina Faso is one of the countries of West Africa, the part of the continent where HIV-2 is endemic and HIV-1 having been introduced first, which would have resulted in the presence of a double HIV-D infection in addition to infection with one of two types..$^{30-34}$ Thus, this study focused on determining the rates of infection with HIV-1, HIV-2 and HIV-D by analyzing data from 66,597 pregnant women serosurveillances of HIV sentinel sites in Burkina Faso between 2006 and 2014. In this population of pregnant women, the proportion of HIV-1 (94.2\%) was predominant in contrast to that of HIV-2 (4.5\%) and HIV-D (1.27\%). These results confirm the high prevalence of HIV-1 in the world and particularly in sub-Saharan Africa. $4,5,12,35$ This disproportion between HIV-1 and HIV-2 is due to the different transmission rates of both viruse ${ }^{36,37}$ including sexual which is low for HIV-2 (estimated at $1 / 3$ that of HIV-1). ${ }^{38,23}$ When the dual infection (HIV-D), low rate can be explained by its low prevalence in West Africa ${ }^{39-41}$ Our findings are opposed to those obtained respectively in Gambia where HIV-1 rate increased over the years from $4.2 \%$ to $17.5 \%$ (1988 to 2003), the HIV-2 decreased by 7, $0 \%$ to $4.0 \%$ and HIV-D was decreased by $1.2 \%$ to $0.8 \% ;{ }^{38}$ Guinea-Bissau evoking an increase in HIV-1 from $0 \%$ to $4.8 \%$ (1987 to 2004) against a decrease in HIV2 $8.3 \%$ to $2.5 \%{ }^{42}$ and in France with a prevalence of $0.1 \%$ (HIV-1), 1.8\% (HIV-2) and 0.2\% (HIV $1+2$ ) between 2003 and $2006 .{ }^{33}$ They are comparable to those achieved in Senegal in women who showed a decline in the relative prevalence of HIV-1 (19901993 ) and a slight increase between (1993-2009), it also lowered HIV2 and HIV1 + 2 was stable (1990-1993) and declined thereafter. ${ }^{43}$ Earlier studies evoked the proportions of the highest HIV-1 than those of HIV-2 in West Africa: Burkina Faso particularly in an area has moderate prevalence these prevalence's were $6.2 \%$ (HIV-1) vs $0,3 \%$ (HIV2), ${ }^{44,45}$ in Burkina Faso in the internal medicine service $91.5 \%$ (HIV-1) vs. $4.6 \%$ (HIV-2), ${ }^{44}$ Niamey $3.1 \%$ (HIV1) against $0.1 \%$ $(\mathrm{HIV} 2)^{4}$ Senegal $1.9 \%$ (HIV1) against $0.7 \%(\mathrm{HIV} 2)^{46}$ and Cotonou 98\% (HIV-1) against 2\% (HIV-2). ${ }^{47,48}$

The rates observed in the current study $(4.5 \%$ (HIV-2) and $1.27 \%$ (HIV-D)), however, were lower than those obtained in Guinea-Bissau $19 \%$ and $11 \%$ between 2005 and 2013 in a population $65 \%$ of women ${ }^{48}$ and higher than those obtained in a population of $67 \%$ women in the Ivory Coast in 2006 and 2007, with 95\% (HIV-1), 2\% and 3\% (HIV2), $3 \%$ and $2 \%(\text { HIV } 1+2)^{49}$

\section{Rate of HIV-I, HIV-2 and HIV-D by region}

In urban areas $(p=0.001)$ and rural $(p=0.007)$ rates varied significantly according to the type of HIV. In urban areas, HIV-1 levels were significantly higher (40.2\%) in the capital of Burkina Faso (Ouagadougou) and the maximum of HIV-2 (22.7\%) was obtained in another city (Ouahigouya). The rate of HIV-2 (83.3\%) and HIV-D $(37.5 \%)$ were remarkably higher in rural areas unlike HIV-1. The high rate of HIV-1 found in the capital would explain the mixing of populations that can be a risk factor for infection with HIV-1.29 These results also support low sexual transmissibility of HIV-2 29,23 and the probable protection of persons infected with HIV-2 against HIV1. ${ }^{36,40,50-52}$ Our results are consistent with those observed in urban Khar in Mumbai (India), where the predominant HIV-1 (93\%) against the HIV-2 (6\%) and HIV-1 + 2 (1\%) between 2006 and 2009..$^{51}$

\section{Rate of HIV-I, HIV-2 and HIV-D by socio-demographic characteristics of women}

Rates varied according to age group and the type of offending HIV ( $\mathrm{p}=0.001)$. They were significantly higher $36.4 \%$ (HIV-1), $23.6 \%$ (HIV-2) and $43.7 \%$ (HIV-D) of 25-29 against the lowest rate among older women (45- 49 years) regardless of the type of HIV. Dual infection recorded the highest proportion compared to single infections. This age group is the active period of sexuality in women. These results explain the high part of sexuality in the transmission of HIV-1 and HIV-D and a similarity in their progression. ${ }^{33}$ Our findings are opposed to those disclosed in Dakar (Senegal) which reported 37.5 years as the mean age of HIV-2 positive subjects and 34.4 years for HIV-1 positive. ${ }^{33}$ The rates were significantly higher $(25 \%$, $25 \%$ and $23.5 \%$ ) for each type of HIV among women who had one child. HIV-1 levels decreased inversely with the parity from 1 child $(p=0.001)$. These results are different from those observed in other studies conducted in Burkina Faso in 2017 that suggested a higher prevalence of HIV among multiparous women ${ }^{41}$ Ethiopia in $2015^{53}$ and Uganda in 2009. ${ }^{54}$ These results would explain why age and parity are not necessarily linked in acquiring HIV infection. The study also found that married women had significantly higher rates of HIV-1 infection $(100 \%)$, HIV-2 (86.2\%) and HIV-D $(84.0 \%)(\mathrm{p}=0.0004)$. Our results are comparable to those found in Burkina Faso in 2017 where unmarried women were more likely to be infected with HIV than those who are married $\left(\mathrm{OR}=1.67^{1.42 \text { to } 1.97} ; \mathrm{p}=0.000\right)^{41}$ and Ethiopia in 2015 with 3.29 the risk of HIV infection among married women compared to those who are not married ${ }^{53}$. These results would show that in addition to its endemic nature, infection would also depend on the genetics of the individual. Household recorded significantly high rates of each of HIV infections $82.2 \%$, respectively (HIV-1), $66.6 \%$ $($ HIV-2) and $38.4 \%($ HIV $1+2)(p=0.002)$. This type of occupation that keeps women at home should cover the activities against the high risk of being infected with HIV. The type of high-risk occupation was associated with a $32 \%$ risk of being infected by HIV in women in Rakai in Uganda in 2014 (Hazard Ratio $=1.32$ [0.99 to 1.75]). ${ }^{55}$ Our results differ from those discussed in Tanzania ${ }^{56}$ with a higher prevalence $(13.1 \%)$ in commercial and Ethiopia ${ }^{53}$ where traders had 2.07 times at risk of HIV infection.

The rate was significantly higher among illiterate women, respectively $(55.2 \%, 71.1 \%$ and $71.4 \%)$ compared to literates and among those with primary education $(21.2 \%, 13.4 \%$ and $14.2 \%)$ versus the next level $(p=0.008)$. The rate of HIV-2 and HIV-D was higher compared to HIV-1 in non-literate women while HIV-1 prevailed among women in the primary level. These results contrast with those of Ghana where women of secondary and tertiary level were less likely to be infected with HIV than those without primary education $(\mathrm{OR}=0.53)^{57}$ and India which revealed that women with less than 11 years of formal education were more likely to have HIV (Adjusted Odds Ratio=2.4). ${ }^{58}$ They are comparable with the highest prevalence (13.4\%) and 3.9\% among non-literate women in Tanzania respectively ${ }^{56}$ and Uganda. ${ }^{54}$ The high prevalence among the less educated could be explained by their low accessibility to the various means of information such as new technologies.

\section{Risk factors associated with HIV-I, HIV-2 and HIV-D in women}

Married pregnant women were more likely to be infected with HIV-1 and HIV-2 compared to unmarried women. This risk was higher for HIV-1 and HIV-2 (odds ratio (OR) $=65.4$ [54.8 to 78.0] against 47.7 [22.4 to 101.7]). These results are different from those obtained in Burkina Faso in $2017^{41}$ where unmarried women had higher risk of HIV infection than married women ( $\mathrm{OR}=1.67$ [1.42 to 1.97]) but they are comparable to results in Ethiopia ${ }^{53}$ with a higher risk among married women ( $\mathrm{OR}=3.29$ [0.43 to 20.00]) compared with unmarried.

Women with one or more parity had more risk of HIV infection compared to primigravidae ( 0 parity). This risk is six times higher for 
HIV-1 versus HIV-2 (odds Ratio=12.6 [10.7 to 14.7]; $\mathrm{p}=0.000$ versus 2.2 [1.02 to 5.07]; $\mathrm{p}=0.03)$. This result is comparable to that found in Burkina Faso in 2017 where women with parity 1 were more likely to be infected with HIV compared with other parities ( $\mathrm{OR}=1.64$ [1.41 to 1.89]) ${ }^{41}$ It is different from that obtained in Uganda ${ }^{54}$ with a higher prevalence of $\operatorname{HIV}(7.5 \%)$ among the three parity parity $1(4.1 \%)$ and that of Ethiopia ${ }^{53}$ stipulating a higher prevalence $(12.2 \%)$ in multiparous against (9.2\%) among primiparous.

All other types of occupation had gathered more risk of infection with HIV-1 compared with pupils and students $(\mathrm{OR}=1,8$ [1.2-2.6] $\mathrm{p}=0.001)$ while the type of occupancy does not constitute a risk for HIV-2 (OR=1.1 [0.2 to 4.7], $\mathrm{p}=0.85)$. This result is different from that mentioned in Uganda stipulating that students had higher risk of HIV infection (AIRR $=0.22) .{ }^{59}$ However, it is comparable to other studies especially in Burkina Faso where pupils and students be exposed to the risk of HIV infection was higher ( $\mathrm{OR}=1.68$ [1.20 to 2.33]) compared to other types of occupation gathered ${ }^{41}$ in Tanzania where prevalence was higher (13.1\%) in commercial $;{ }^{53}$ in Ethiopia with a prevalence of 2.07 times higher in the shopping $(\mathrm{OR}=2.07$ [0.46 to 8.8553$]$.

Non-literate women were more likely to be infected by HIV-D (odds ratio $=137.5$ [17.5 to 1074.7]; $\mathrm{p}=0.000$ ) compared to literate women and schooling was not a risk for HIV-1 (Odds Ratio=1 [0.7-1.3]; $\mathrm{p}=0.9$ ) and HIV-2 (odds Ratio=3.2 [0.4 to 23.3]; $\mathrm{p}=0.2$ ). This result contrasts with that obtained in Ghana where ${ }^{57}$ women of secondary and tertiary levels had a higher risk of being infected with $\mathrm{HIV}$ than those who did not reach the primary level $(\mathrm{OR}=0.5)$ and in India suggesting that women with less than 11 years of schooling had less risk of infection (Adjusted Odds Ratio $=2.4$ ). ${ }^{58}$

Women aged 20-49 were more likely to be infected by HIV-1 (odds ratio $=72.9$ [56.4 to 94.3]; $\mathrm{p}=0.000$ ) and HIV-2 (Odds Ratio $=2.7$ [1.002 to 7.6], $\mathrm{p}=0.04$ ) compared to $15-19$. This risk was 72.9 times for HIV-1 versus 2.7 times for HIV-2. These results are comparable to that found in Burkina Faso where women aged 20-49 years had higher risk of HIV infection $(\mathrm{OR}=3.14$ [2.51 to 3.93]; $\mathrm{p}=0.000){ }^{41}$; in Tanzania 25-34ans of women had increased risk of infection at HIV $(\mathrm{COR}=1.97$ [1.79 to 2.16], $\mathrm{p}<0.05)$ than those of 35 or more $(\mathrm{COR}=1.88$ [1.62 to 2.17$], \mathrm{p}<0.05) .{ }^{59}$

Women who have a residence time of a year or more in their health locality had more risk of infection by HIV-1 $(\mathrm{OR}=4.3[3.7$ to 5.1]; $\mathrm{p}=0.000$ ) compared to those who have less than a year. However, the residence time was no risk for HIV-2 (OR=1.0 [0.4-2.5]; $\mathrm{p}=0.8)$ and $\mathrm{HIV} 1+2(\mathrm{OR}=1,0[0.2$ to 4.4$], \mathrm{p}=0.9)$. Our results differ from that observed in Burkina Faso in 2017 by Konate et al. where the length of stay of less than one year was most at risk of HIV infection compared to the duration of one year or more $\left((\mathrm{OR}=5.33\right.$ [4.61 to 10.16] $){ }^{41}$ Overall, the highest risk of infection by HIV-1 obtained in the study compared to HIV-2 is explained by the low transmissibility of HIV-2 compared to HIV-1.23,29

\section{Conclusion}

At the end of these nine years of study, there was a high variability in the rates of different types of HIV (HIV-1, HIV-2 and HIV-D) in Burkina Faso by urban and rural areas and sociodemographic characteristics of women. HIV-1 remains the most prevalent with a higher risk of infection compared to HIV-2. Associated risk factors were to be married, have parity 1 or more, be illiterate and be aged 2049 years and one year in length of stay or more in the health locality. The consideration of these factors thus identified in the development of national programs greatly help to reduce the national prevalence in Burkina Faso.

\section{Acknowledgments}

None.

\section{Conflicts of interest}

None.

\section{Funding}

None.

\section{References}

1. Hughes A, Corrah T. Human Immunodeficiency Virus type 2 (HIV2). Blood Rev. 1990;4(3):158-164

2. Benoit Visseaux, Charlotte Charpentier, Margarita Hurtado-Nedele,et al. Phenotypic in vitro Susceptibility of HIV-2 Clinical Isolates to CCR5 Inhibitors. Antimicrob Agents Chemother. 2012;56(1):137-139.

3. Ouesseini H, Pecarrere JL, Medard D, et al. Evolution of the prevalence of HIV1 and HIV2 infections at National Hospital of Niamey - Niger. Bull Soc Pathol Exot. 1991;84(3):235-239.

4. Mamadou S, Laouel Kader A, Rabiou S, et al. Prevalence of infection from HIV and five other sexually transmitted infections among sex workers in Niamey, Niger. Bull Soc Pathol Exot. 2006; 99(1):19-22.

5. Mansson F, Camara C, Biai A, et al. High prevalence of HIV-1, HIV-2 and other sexually Transmitted infections Among women Attending two sexual health clinics in Bissau, Guinea-Bissau, West Africa. Int J STD AIDS. 2010;21(9):631-635.

6. Saag MS. AIDS testing now and in the future. The Medical Management of AIDS. 1995;65:85.

7. Gurtler L. Difficulties and strategies of HIV diagnosis. Lancet. 1996;348(9021):176-179.

8. Gupta P, Kingsley L, Sheppard HW, et al. High incidence and prevalence of HIV-1 infection in high risk population in Calcutta, India. Int J STD AIDS. 2003;14(7):463-468.

9. Salima Bouzeghoub, El Hadj Belabbesa. La diversité génétique du VIH1 et données actuelles en Algérie. Revue Francophone des Laboratoires. 2007;396(Supp 1):17-20.

10. Romero A, Sued O, Puig T, et al. Prevalence of Tramsmitted Antiretroviral Resistance and Distribution of HIV-1 Subtypes Among Patients with Recent Infection in California (Spain) between 2003 and 2005. Enferm Infecc Microbiol Clin. 2011;29(7):482-489.

11. Forbi JC, Entonu PE, Mwangi LO, et al. Estimates of human immunodeficiency virus incidence ampng female sex workers in north central Nigeria: implications for HIV clinical trials. Trans $R$ Soc Trop Med Hyg. 2011;105(11):655-660.

12. Philippe Msellati, Charlotte Sakarovitch, Laurence Bequet, et al Decrease of human immunodeficiency virus prevalence in antenatal clinics in Abidjan, Ivory Coast, 1995-2002. International Journal of STD \& AIDS. 2006;17(1):57-60.

13. G Remy. Image géographique des infections à VIH en Afrique de l'ouest. Médecine d'Afrique noire. 1993;40(1):1-7.

14. Solomon S, Kumarasamy N, Ganesh AK, et al. Prevalence and risk factors of HIV-1 and HIV-2 infection in urban and rural areas in Tamil Nadu, India. Int J STD AIDS. 1998;9(2):98-103.

15. Broutet N, Sousa Queiroz A, Basilio FP, et al. Prevalence of HIV-1, HIV2 and HTLV antibody, in Fortaleza, Ceara, Brazil, 1993-1994. Int J STD AIDS. 1996;7(5):365-369.

16. Kageyama S, Maniar JK, Iwasaki H, et al. Seronegative HIV-2 carriers in India. Int J STD AIDS. 2000;11(1):31-37. 
17. Matemo D, Kinuthia J, John F, et al. Indeterminate Rapid HIV-1 test results among antenatal and postnatal mothers. Int $J$ STD AIDS 2009;20(11):790-792.

18. Delaugerre C, Simon F. Tout sur les tests de dépistage rapide. Transcriptases. 2009;141:35.

19. Phillips S, Granada TC, Pau PC, et al. Diagnosis of Human Immunodeciency virus type 1 infection with different subtypes using rapid tests. Clin Diagn Lab Immunol. 2000;7(4):698-699.

20. Reynolds SJ1, Ndongala LM, Luo CC, et al. Evaluation of a rapid test for the detection of antibodies to human immunodeficiency virus type 1 and 2 in the setting of multiple viral subtypes Transmitted. Int J STD AIDS. 2002;13(3):171-173.

21. Gilbert PB, McKeague IW, Eisen G, et al. Comparison of HIV-1 and HIV-2 infectivity from a prospective cohort study in Senegal. Stat Med. 2003;22(4):573-593.

22. Poveda E, Briz V, Soriano V. Enfuvirtide, the first fusion inhibitor to treat HIV infection. AIDS Rev. 2005;7(3):139 -147.

23. Ren J, Bird LE, Chamberlain PP, et al. Structure of HIV-2 reverse transcriptase at 2.35-A resolution and the mechanism of resistance to non-nucleoside inhibitors. Proc Natl Acad Sci USA. 2002;99(22):14410-14415.

24. Witvrouw M, Pannecouque C, Switzer WM, et al. Susceptibility of HIV-2, SIV and SHIV tovarious HIV-1 compounds: implications for treatment and postexposure prophylaxis. Antivir Ther. 2004;9(1):57-65.

25. WHO. Revised recommendations for the selection and use of HIV antibody tests. Wkly Epidemiol Rec. 1997;72(12):81-88.

26. WHO. Unlinked anonymous screening for the public health monitoring of HIV infections. Proposed international guidelines. Geneva: WHO, Switzerland. 1989.

27. Schim van der Loeff MF, Sarge Njie R, Ceesay S, et al. Regional differences in HIV trends in The Gambia: results from Sentinel Surveillance Among pregnant women. AIDS. 2003;17(12):1841-1846.

28. Fultz PN, Switzer WM, Schable CA, et al. Seroprevalence of HIV-1 and HIV-2 in Guinea-Bissau in 1980. AIDS. 1988;2(2):129-132.

29. Fleming AF. Seroepidemiology of human immunodeficiency viruses in Africa. Biomed Pharmacother. 1988;42(5):309-320.

30. Kawamura M, Yamazaki S, Ishikawa K, et al. HIV-2 in West Africa in 1966. Lancet. 1989;1(8634):385.

31. Lemey P, Pybus OG, Wang B, et al. Tracing the origin and history of the HIV-2 epidemic (2003). Proc Natl Acad Sci USA. 2003;100(11):6588-6592.

32. Heitzinger K, Sow PS, Dia Badiane NM, et al. Trends of HIV-1, HIV-2 infection in women and dual Attending outpatient clinics in Senegal, 1990-2009. Int J STD AIDS. 2012;23(10):710-716.

33. Gottlieb GS, Eholié SP, Nkengasong JN, et al. A call for randomized controlled trials of antiretroviral therapy for HIV-2 infection in West Africa. AIDS. 2008;22(16):2069-2072.

34. Serge Eholie, Xavier Anglaret. Commentary: Decline of HIV-2 prevalence in West Africa: good news or bad news? Int J Epidemiol. 2006;35(5):1329-1330.

35. Djomand G, Greenberg AE, Sassan Morokro M, et al. The epidemic of HIV/AIDS in Abidjan, Cote d'Ivoire: a review of data collected by Projet RETRO-CI from 1987 to 1993. J Acquir Immune Defic Syndr Hum Retrovirol. 1995;10(3):358-365.

36. Larsen O, Z da Silva, Sandstrom A, et al. Declining HIV-2 prevalence and incidence Among Men in a community study from Guinea-Bissau. AIDS. 1998;12(13):1707-1714.

37. van der Loeff MF1, Awasana AA, Sarge-Njie R, et al. Sixteen years of HIV surveillance in a West African research clinic Reveals divergent epidemic trends of HIV-1 and HIV-2. Int $J$ Epidemiol. 2006;35(5):1322-1328.

38. Landman R, Damond F, Gerbe J, et al. Immunovirological and therapeutic follow up of HIV-1 / HIV-2 dually seropositive patients. AIDS. 2009;23(3):423-443.

39. Omobolaji T Campbell Yesufu, Rajesh T Gandhi. Update on Human Immunodeficiency Virus (HIV) Infection -2. Clinical Infectious Diseases. 2011;52(6):780-787.

40. Konaté D, Dahourou H, Traore W, et al. Risk factors associated with HIV prevalence in pregnant women in Burkina Faso, from 2006 to 2014. Afr J cln exper Microbiol. 2017;18(2):92- 101.

41. Månsson F, Alves A, Silva ZJ, et al. Trends of HIV-1 and HIV-2 prevalence Among pregnant women in Guinea-Bissau, West Africa: Possible effect of the civil war 1998-1999. Sex Transm Infect. 2007;83(6):463-467.

42. Barin F, Cazein F, Lot F, et al. Prevalence of HIV-2 and HIV-1 Group O infections Among new HIV diagnoses in France: 2003-2006. AIDS. 2007;21(17):2351-53.

43. Sangaré L, Sombié R, Combasséré AW, et al. Antenatal transmission of hepatitis B prevalence in moderate area of HIV, Ouagadougou, Burkina Faso. Bull Soc Pathol Exot. 2009;102(4):226-229.

44. Ndiaye P, Diedhiou A, Ly D, et al. Prévalence du VIH/Sida chez les clients du centre de dépistage volontaire anonyme et d'accompagnement de Pikine/Guédiawaye, au Sénégal. Med Trop. 2008; 68:277.

45. Ouédraogo DD, Lompo PC, Tieno H, et al. Rheumatic disorders Observed in HIV infected patients Undergoing highly active antiretroviral therapy (HAART) has 366 prospective case study in Burkina Faso. Med Trop. 2010;70(4):345-348

46. Atadokpede F, Yedomon H, Adegbidi H, et al. Manifestations cutanéomuqueuses des personnes vivant avec le virus de l'immunodéficience humaine à cotonou, bénin. Med Trop. 2008;68(3):273-276.

47. Jespersen S, Honge BL, Esbjörnsson J, et al. Differential effects of sex in a West African cohort of HIV-1, HIV-2 and HIV-1/2 dually infected patients: men are worse off. Trop Med Int Health. 2016;21(2):253-262.

48. Andrew F Auld, A Kunomboa Ekra, Ray W Shiraishi, Moses Z Tuho, Joseph S Kouakou, et al. (2014) Temporal Trends in Treatment Outcomes for HIV-1 and HIV-2-Infected Adults Enrolled in Ivory Coast's National Antiretroviral Therapy Program. PLoS ONE 9(5): e98183.

49. Travers K, Mboup S, Marlink R, et al. Natural protection against HIV-1 infection Provided by HIV-2. Science. 1995;268(5217):1612-1615.

50. Chiara M, Rony Z, Homa M, et al. Characteristics, immunological response \& treatment outcomes of HIV-2 Compared with HIV-1 \& dual infection (HIV 1/2) in Mumbai. Indian J Med Res. 2010; 132(6):683-689.

51. Kanki PJ, Rowland Jones S. The protective effect of HIV-2 infection: implications for understanding HIV-1 immunity. AIDS. 2014;28 (7):1065-1067.

52. Mengistu E, Tekalign D, Yeshambel B, et al. Seroprevalence of syphilis and human immunodeficiency virus infections Among pregnant women Who expects the University of Gondar teaching hospital, Northwest Ethiopia: a cross sectional study. BMC Infect Dis. 2015;15:111.

53. Musinguzi J, W Kirungi Opio A, Montana L, et al. Comparison of HIV Prevalence Estimates From National Sentinel Surveillance and Population has-Based Survey in Uganda, 2004-2005. J Acquir Immune Defic Syndr. 2009;51:78-84.

54. Kagaayi J, Gray RH, Whalen C, et al. Indices to Measure Risk of HIV Acquisition in Rakai, Uganda. PLoS ONE. 20149(4):e92015.

55. Mmbaga EJ, Akhtar H, Germana HL, et al. Prevalence and risk factors for HIV-1 infection in rural Kilimanjaro Region of Tanzania: Implications for prevention and treatment. BMC Public Health. 2007;7:58. 
56. Orish VN, Onyeabor OS, Boampong JN, et al. Influence of education on HIV Infection Among pregnant women prenatal care Attending Their in Sekondi-Takoradi metropolis, Ghana. J Health Care Poor Underserved. 2014;25(3):982-990.

57. Darak S, Gadgil M, Balestre E, et al. HIV risk perception Among pregnant women in western India: need for Reducing vulnerabilities Rather than Improving knowledge! AIDS Care. 2014; 26(6):709-715.
58. Santelli JS, Edelstein ZR, Mathur S, et al. Behavioral, Biological, and Demographic Risk and Protective Factors for New HIV Infections Among Youth, Rakai, Uganda. 2013. J Acquir Immune Defic Syndr. 2013;63(3):393-400.

59. Manyahi J, Jullu BS, Abuya MI, et al. Prevalence of HIV and syphilis infections Among pregnant women Attending antenatal clinics in Tanzania, 2011. BMC Public Health. 2015;15:501. 